\title{
贺兰山西坡主要山地灌丛群落的基本特征
}

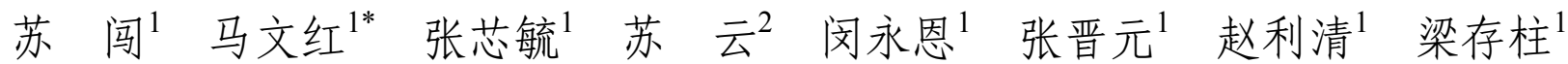

${ }^{1}$ 内蒙古大学生态与环境学院, 呼和浩特 $010000 ;{ }^{2}$ 内蒙古贺兰山国家级自然保护区管理局, 阿拉善左旗, 内蒙古 750306

摘 要 灌从是贺兰山最主要的植被组分, 但关于该地区灌从群落的专门研究并不多见。为了解该地区灌从资源的分布及生 长状况, 该研究对内蒙古贺兰山国家级自然保护区内主要的山地灌从群落进行样方调查, 通过分析样方数据, 量化描述了各 群落的基本特征。结果表明: 贺兰山自然保护区沿海拔梯度主要有准噶尔栒子群系(Form. Cotoneaster soongoricus)、紫丁香 群系(Form. Syringa oblata)、小叶金露梅群系(Form. Potentilla parvifolia)、虎榛子群系(Form. Ostryopsis davidiana)、小叶忍冬 群系(Form. Lonicera microphylla)、银露梅群系(Form. Potentilla glabra)、山生柳群系(Form. Salix oritrepha)和鬼箭锦鸡儿群系 (Form. Caragana jubata) 8 种主要的山地灌从群系。

关键词 贺兰山; 山地灌从; 群落特征; 物种组成

苏问, 马文红, 张芯艈, 苏云, 闵永恩, 张晋元, 赵利清, 梁存柱 (2018). 贺兰山西坡主要山地灌从群落的基本特征. 植物生态学报, 42, 1050-1054. DOI: $10.17521 /$ cjpe.2018.0111

\section{Species composition and structure characteristics of the major montane shrub communities in the west slope of Helan Mountains, Nei Mongol, China}

SU Chuang ${ }^{1}$, MA Wen-Hong ${ }^{1 *}$, ZHANG Xin-Yu ${ }^{1}$, SU Yun ${ }^{2}$, MIN Yong-En ${ }^{1}$, ZHANG Jin-Yuan ${ }^{1}$, ZHAO Li-Qing $^{1}$, and LIANG Cun-Zhu ${ }^{1}$

${ }^{1}$ School of Ecology and Environment, Inner Mongolia University, Hohhot 010000, China; and ${ }^{2}$ Helan Mountains National Nature Reserve of Nei Mongol, Alxa Zuoqi, Nei Mongol 750306, China

\begin{abstract}
Scrubland is the most important vegetation component in Helan Mountains, Nei Mongol, but remians very poorly studied. In order to understand the distribution and growth status of the scrubland resources in this area, the shrub communities in the National Nature Reserve of Helan Mountains were sampled. Using the community data, the characteristics of the community structure were quantitatively analyzed. The results show that the shrub communities along an altitudinal gradient in the National Nature Reserve of Helan Mountains include the following formations: Form. Cotoneaster soongoricus, Form. Syringa oblata, Form. Potentilla parvifolia, Form. Ostryopsis davidiana, Form. Lonicera microphylla, Form. Potentilla glabra, Form. Salix oritrepha and Form. Caragana jubata. Furthermore, we also provide the data on species composition and structures of these montane shrub communities, which could provide insight for the conservation and management of these valuable communities.
\end{abstract}

Key words Helan Mountains; montane shrub; community characteristics; species composition

Su C, Ma WH, Zhang XY, Su Y, Min YE, Zhang JY, Zhao LQ, Liang CZ (2018). Species composition and structure characteristics of the major montane shrub communities in the west slope of Helan Mountains, Nei Mongol, China. Chinese Journal of Plant Ecology, 42, 1050-1054. DOI: 10.17521/cjpe.2018.0111

灌从是以灌木为优势种的植被类型, 高度在 $5 \mathrm{~m}$ 以下，覆盖度大于 $30 \%$, 通常与森林、草地并称 为三大陆地自然生态系统。灌从生态系统不仅在群 落的演替过程中扮演着极其重要的角色, 而且在资 源植物、区域生态环境保护等方面也起着非常重要 的作用(胡会峰等, 2006)。
贺兰山是内蒙古境内海拔最高的山地, 作为西 北干旱区一条极为重要的生态屏障(刘秉儒，2010), 贺兰山在阻隔腾格里沙漠的东移, 以及拦截起源于 阿拉善的沙尘暴等方面起着巨大的作用(郑敬刚等, 2008)。贺兰山是温带草原与荒漠的分界线, 地理位 置特殊, 自然环境复杂, 植被类型多样并且具有一

收稿日期Received: 2018-05-15 接受日期Accepted: 2018-09-11

基金项目：国家科技基础性工作专项(2015FY110300)。Supported by the National Special Project of Basic Work of Science And Technology (2015FY110300).

* 通信作者Corresponding author (whmapku@126.com) 
定的过渡特征, 是内蒙古多个区域生物多样性中心 的核心区域，也是我国西北干旱区一个重要的生物 资源宝库(梁存柱等, 2004)。灌丛在贺兰山的植被组 成方面扮演着重要角色, 种类丰富的灌从类型对于 丰富干旱区的生物多样性以及生态系统功能具有重 要的调控作用。

植物群落调查的样方数据是揭示植物群落结构 和物种组成等特征的重要依据(张维康等, 2013), 为 植被生态学与群落生态学研究提供了重要基础。目 前关于该地区主要灌从群落的专门研究未见报道。 因此, 量化描述贺兰山自然保护区主要灌从群落的 基本结构和物种组成等特征, 对揭示该地区灌从资 源的分布, 服务于生物多样性保育以及科学管理 等具有重要意义。综上所述, 本文在内蒙古贺兰山 自然保护区沿海拔梯度详细调查了主要的山地灌 从群落(包括海拔 $2800 \mathrm{~m}$ 以上的高山灌丛), 并以样 方数据为依托, 详细描述了每个山地灌从群落的基 本特征, 以期为该地区后续的植被研究提供基础 资料。

\section{1 材料和方法}

\section{1 研究区概况}

贺兰山坐落在我国温带草原与荒漠的过渡地带 (朱源等, 2008), 地处蒙古高原阿拉善荒漠的东南边 缘, 地理坐标 $37.67^{\circ}-39.50^{\circ} \mathrm{N}, 105.33^{\circ}-106.67^{\circ} \mathrm{E}$ 。 山脉总体为东北一西南走向, 主峰海拔高达 $3556 \mathrm{~m}$, 是内蒙古境内最高的山峰。由于深居内陆, 贺兰山 具有典型的温带大陆性气候特征。山体日照充足, 无霜期仅 60-70天, 年均气温由山前的 $7.3{ }^{\circ} \mathrm{C}$ 到主峰 的 $-0.9{ }^{\circ} \mathrm{C}$; 年降水量垂直分异明显并且年际间变 化很大, 降水跨度由山麓的 $200 \mathrm{~mm}$ 到顶峰的
$500 \mathrm{~mm}$ (气候数据来自原宁夏高山气象站), 6-8月 降水最为集中，占全年降水量的 $60 \%-80 \%$ (梁存柱 等, 2004; 刘秉儒, 2010)。贺兰山的海拔高差超过2 $000 \mathrm{~m}$, 植被类型丰富且垂直变化明显，沿海拔梯 度可将其划分为 4 个垂直植被带：山前荒漠与荒漠 草原带-山麓与低山草原、灌从带-中山针叶林带-高 山、亚高山灌丛草甸带(李志刚等, 2012)。东西坡的 分异，南、北、中各段的差别，加之地形、地貌、坡 向和土壤的变化, 形成贺兰山地区复杂多样的自然 环境。

\section{2 样地调查}

\subsection{1 样方设置}

植被调查于 2017年7-8月，在内蒙古自治区阿 拉善左旗贺兰山自然保护区内进行。样点的布设主 要兼顾如下原则：1)灌从群落在该地区具有地域代 表性; 2)对于分布面积虽小，但是具有科学、经济、 生态、珍稀等重要价值的灌从类型也纳入到调查范 围；3)在上述原则的基础上，结合实际考虑调查的 可到达性等因素。沿海拔梯度选择连片分布、斑块 面积大于 $100 \mathrm{~m} \times 100 \mathrm{~m}$ 的灌从群落, 选取群落生 境、内部结构和物种组成相对均匀的样地, 沿对角 线设置 3 个 $5 \mathrm{~m} \times 5 \mathrm{~m}$ 的大样方, 调查灌木及乔木, 在每个大样方内沿对角线布置 3 个 $1 \mathrm{~m} \times 1 \mathrm{~m}$ 的小样 方进行草本层、灌木更新层和苔藓层调查, 累计布 设 8 个样地, 24 个大样方和 72 个小样方。 8 个样地的基 本信息见表 1 , 详细样方数据见附录。

\subsection{2 调查内容}

本研究的调查内容包括：1)样地基本信息, 包 括调查地点、优势灌从群落类型、经纬度、海拔、 坡向、坡度、有无干扰及干扰强度和干扰类型等。 干扰类型包括自然(气候灾害、地质灾害)、火烧、

表1 贺兰山样地基本信息

Table 1 The locations, topography and disturbance levels of the sampled plots in Helan Mountains

\begin{tabular}{|c|c|c|c|c|c|c|c|c|}
\hline $\begin{array}{l}\text { 样地 } \\
\text { Plots }\end{array}$ & $\begin{array}{l}\text { 纬度 } \\
\text { Latitude (N) }\end{array}$ & $\begin{array}{l}\text { 经度 } \\
\text { Longitude (E) }\end{array}$ & $\begin{array}{l}\text { 海拔 } \\
\text { Altitude (m) }\end{array}$ & $\begin{array}{l}\text { 坡向 } \\
\text { Slope aspect }\end{array}$ & $\begin{array}{l}\text { 坡度 } \\
\text { Slope gradient }\end{array}$ & $\begin{array}{l}\text { 坡位 } \\
\text { Slope position }\end{array}$ & $\begin{array}{l}\text { 干扰类型 } \\
\text { Disturbance type }\end{array}$ & $\begin{array}{l}\text { 干扰强度 } \\
\text { Disturbance } \\
\text { intensity }\end{array}$ \\
\hline S1 & $38.68^{\circ}$ & $105.82^{\circ}$ & 2060 & 北坡 N & $31^{\circ}$ & 中部 Mid slope & - & - \\
\hline S2 & $38.66^{\circ}$ & $105.81^{\circ}$ & 2074 & 北坡 N & $46^{\circ}$ & 中部 Mid slope & - & - \\
\hline S3 & $38.68^{\circ}$ & $105.83^{\circ}$ & 2179 & 西南坡 SW & $24^{\circ}$ & 中部 Mid slope & 放牧 Grazing & 中度 Fairly \\
\hline $\mathrm{S} 4$ & $38.66^{\circ}$ & $105.82^{\circ}$ & 2196 & 西北坡 NW & $31^{\circ}$ & 中部 Mid slope & - & - \\
\hline S5 & $38.87^{\circ}$ & $105.91^{\circ}$ & 2333 & 北坡 N & $35^{\circ}$ & 中部 Mid slope & - & - \\
\hline S6 & $38.83^{\circ}$ & $105.94^{\circ}$ & 2876 & 西坡 W & $26^{\circ}$ & 上部 Upper slope & - & - \\
\hline S7 & $38.83^{\circ}$ & $105.94^{\circ}$ & 3053 & 西坡 W & $39^{\circ}$ & 上部 Upper slope & - & - \\
\hline S8 & $38.84^{\circ}$ & $105.95^{\circ}$ & 3472 & 西坡 W & $20^{\circ}$ & 上部 Upper slope & - & - \\
\hline
\end{tabular}


人为放牧、砍伐、工程建设等, 干扰强度分为无干 扰、轻微、中度和重度干扰; 若草本层受到影响而 灌木层未受影响则视为轻微干扰; 当灌木层受到轻 微影响时视为中度干扰; 若灌木层物种组成或优势 种生长受到较大影响, 则视为重度干扰。2)对于乔 木层, 记录样方内出现的所有乔木种的物种名称、 高度和胸围。3)对灌木层, 目测样方内灌木层群落 总盖度, 详细调查灌木物种名称、每种灌木的最大 高度、平均高度、冠幅(长轴和短轴)、茎秆平均基 径, 以及样方内的灌木物种数和植株个体数(株从 数)等。4)对于草本层, 目测样方内草本层群落总盖 度, 详细调查并记录草本物种名称、盖度、高度、 物种数和多度级。5)在 $1 \mathrm{~m} \times 1 \mathrm{~m}$ 的小样方内记录苔 藓层总盖度, 对于灌木物种的更新苗, 记录其物种 名称、平均高度、多度级等信息。野外采集所调查 到的乔木、灌木和草本植物标本, 室内鉴定准确物 种名称。

\subsection{3 土壤理化性质测定}

群落特征调查完成后, 在每个 $5 \mathrm{~m} \times 5 \mathrm{~m}$ 样方内 沿对角线选择 3 个点, 去除未分解及半分解的调落 物层, 采集0-20 cm深的土壤样品, 混合均匀后装入 塑封袋, 带回实验室进行土壤理化性质分析。利用 台式pH仪(METTLER TOLEDO Fe20-K, MettlerToledo, Zurich, Switzerland)测定土壤酸碱度(水:土= 2.5:1); 采用重铬酸钾容量法测定土壤有机质含量, 运用元素分析仪(vario MACRO cube, Elementar, Hanau, Germany) 采用燃烧法测定全氮含量, 利用激 光粒度仪(Microtrac S3500, Microtrac, Orlando, USA) 测定土壤粒径各组分的百分含量, 并判断土壤质 地。

\section{3 数据分析}

详细统计各样方中的物种数目, 分别计算灌木 (含灌木状乔木)和草本物种的重要值(IV), 公式为:

$$
I V(\%)=(\text { 相对高度 }+ \text { 相对盖度 }+ \text { 相对频度 }) / 3
$$

\section{2 结果分析}

本研究沿海拔梯度共调查内蒙古贺兰山地区 8 个主要的山地灌从群系, 记录种子植物 38 科 95 属 142 种, 其中灌木物种(包括灌木状的青海云杉 (Picea crassifolia)和杜松(Juniperus rigida)及半灌木 或小半灌木贺兰山女蒿(Hippolytia kaschgarica))分 布有限, 共记录 12 科 17 属 22 种, 而草本物种类型较
为丰富, 包括 30 科79属 120 种, 各群系的结构要素、 物种组成等主要特征如下。

\section{1 准噶尔栒子灌丛(Form. Cotoneaster soongoricus)}

土壤为砂壤土, 有机质含量约为 $22.8 \mathrm{~g} \cdot \mathrm{kg}^{-1}$, 全 氮含量为 $0.15 \%, \mathrm{pH}$ 值约为 8.37 。样方数据(附录: 表 1-4)显示, 灌木层总盖度 60\%, 高度变化幅度31-86 $\mathrm{cm}$, 平均高度为 $44 \mathrm{~cm}$, 物种丰富度 7 , 主要物种有 准噶尔栒子(Cotoneaster soongoricus)、毛枝蒙古绣 线菊(Spiraea mongolica var. tomentulosa)、置疑小檗 (Berberis dubia)、小叶金露梅(Potentilla parvifolia)、 荒漠锦鸡儿(Caragana roborovskyi)、狭叶锦鸡儿 (Caragana stenophylla) 和黄刺玫(Rosa xanthina)。草 本层总盖度 $20 \%$, 高度范围 $0.3-18.6 \mathrm{~cm}$, 平均高度 $6.6 \mathrm{~cm}$, 物种丰富度 25 , 主要物种有黄芩(Scutellaria baicalensis)、火线草(Leontopodium leontopodioides)、 碱苑(Tripolium vulgare)、柄状臺草(Carex pediformis)、南牡蒿(Artemisia eriopoda)、山丹(Lilium pumilum)、白蓝翠雀花(Delphinium albocoeruleum) 等。灌木更新层高度范围1.3-6.9 cm, 平均高度 $3.9 \mathrm{~cm}$, 物种丰富度 3 , 有更新的灌木物种为置疑小 檗、荒漠锦鸡儿和小叶金露梅等, 苔藓层总盖度为 $0.3 \%$ 。

\section{2 紫丁香灌丛(Form. Syringa oblata)}

土壤为砂壤土, 有机质含量约为 $164.1 \mathrm{~g} \cdot \mathrm{kg}^{-1}$, 全氮含量 $0.63 \%, \mathrm{pH}$ 值约为 7.17 。样方数据(附录: 表 5-8)显示, 灌木层总盖度 $80 \%$, 高度变化幅度 14-125 $\mathrm{cm}$, 平均高度为 $58 \mathrm{~cm}$, 物种丰富度 11 , 主要物种有 紫丁香(Syringa oblata)、准噶尔栒子、置疑小檗、 黄刺玫、小叶忍冬(Lonicera microphylla)、蒙古绣线 菊(Spiraea mongolica)等。草本层总盖度 $35 \%$, 高度 范围0.2-32.3 cm, 平均高度 $5.8 \mathrm{~cm}$, 物种丰富度 34 , 主要物种有干生薹草(Carex aridula)、阿拉善我观草 (Roegneria alashanica)、小红菊 (Chrysanthemum chanetii)、西山委陵菜(Potentilla sischanensis)、头状 石头花(Gypsophila capituliflora)、碱苑、北柴胡 (Bupleurum chinense)、西藏点地梅 (Androsace mariae) 等。灌木更新层高度0.4-9.2 cm, 平均高度 $4.3 \mathrm{~cm}$, 物种丰富度 6 , 有更新的物种有紫丁香、小 叶金露梅、置疑小檗、准噶尔栒子等, 苔藓层总盖 度 $4 \%$ 。

\section{3 小叶金露梅灌丛(Form. Potentilla parvifolia)}

土壤为砂壤土, 有机质含量约为 $11.0 \mathrm{~g} \cdot \mathrm{kg}^{-1}$, 全 
氮含量为 $0.04 \%, \mathrm{pH}$ 值约为 8.49 。样方数据(附录: 表 9-12)显示, 灌木层总盖度 35\%, 高度变化幅度 20-60 cm, 平均高度为 $40 \mathrm{~cm}$, 物种丰富度 6 , 主要 物种有小叶金露梅、小叶忍冬、置疑小檗、准噶尔 栒子、紫丁香、三裂绣线菊(Spiraea trilobata)等。 草本层总盖度 $35 \%$, 高度范围 $0.3-41.8 \mathrm{~cm}$, 平均高 度 $8.7 \mathrm{~cm}$, 物种丰富度 28 , 主要物种有龙蒿 (Artemisia dracunculus)、碱苑、甘青针茅(Stipa przewalskyi)、黄囊臺草(Carex korshinskyi)、芨芨草 (Achnatherum splendens)、狼针草(Stipa baicalensis)、 星毛委陵菜(Potentilla acaulis)、阿拉善我观草等。 灌木更新层高度 $5.3 \mathrm{~cm}$, 物种丰富度 1 , 小叶金露梅 有更新苗, 苔藓层缺如。

\section{4 虎榛子灌丛(Form. Ostryopsis davidiana)}

土壤为砂壤土, 有机质含量约为 $207.5 \mathrm{~g} \cdot \mathrm{kg}^{-1}$, 全氮含量为 $0.87 \%, \mathrm{pH}$ 值约为 7.40 。样方数据(附录: 表13-16)显示, 灌木层总盖度 $105 \%$, 高度变化幅度 10-131 cm, 平均高度为 $51 \mathrm{~cm}$, 物种丰富度 12 , 主 要物种有虎榛子(Ostryopsis davidiana)、小叶忍冬、 紫丁香、蒙古绣线菊、银露梅(Potentilla glabra)、 置疑小檗等。草本层总盖度 $15 \%$, 高度范围 $0.3-13.3$ $\mathrm{cm}$, 平均高度 $2.7 \mathrm{~cm}$, 物种丰富度 19 , 主要物种有 柄状薹草、东亚唐松草(Thalictrum minus var. hypoleucum)、玉竹(Polygonatum odoratum)、碱苑、阿拉 善黄耆(Astragalus alaschanus)、蔓茎蝇子草(Silene repens)、远志(Polygala tenuifolia)等。灌木更新层高 度 $0.2-15.6 \mathrm{~cm}$, 平均高度 $5.4 \mathrm{~cm}$, 物种丰富度 6 , 灌 木物种虎榛子、紫丁香、蒙古绣线菊、置疑小檗等 有更新，苔蘚层总盖度 $1.6 \%$ 。

\section{5 小叶忍冬灌丛(Form. Lonicera microphylla)}

土壤为砂壤土, 有机质含量约为 $10.8 \mathrm{~g} \cdot \mathrm{kg}^{-1}$, 全 氮含量为 $0.07 \%, \mathrm{pH}$ 值约为 8.47 。样方数据(附录: 表 17-20)显示, 灌木层总盖度 $40 \%$, 高度变化幅度 36-122 cm, 平均高度为 $81 \mathrm{~cm}$, 物种丰富度 5 , 主要 物种有小叶忍冬、蒙古绣线菊、小叶金露梅、叉子 圆柏(Juniperus sabina)和置疑小檗等。草本层总盖 度 $40 \%$, 高度范围 $0.3-43.3 \mathrm{~cm}$, 平均高度 $7.5 \mathrm{~cm}$, 物 种丰富度 37 , 主要物种有阿拉善我观草、短尾铁线 莲 (Clematis brevicaudata) 、白花枝子花 (Dracocephalum heterophyllum)、干生薹草、蒙古蒿 (Artemisia mongolica)、垂穗披碱草(Elymus nutans)、 蒝麻(Potentilla anserina)等。灌木更新层高度范围
1.3-6.8 cm, 平均高度 $3.8 \mathrm{~cm}$, 物种丰富度 5 , 有更新 的物种为蒙古绣线菊、小叶金露梅等, 苔藓层总盖 度为 $8.3 \%$ 。

\section{6 银露梅灌丛(Form. Potentilla glabra)}

土壤为砂壤土, 有机质含量约为 $24.4 \mathrm{~g} \cdot \mathrm{kg}^{-1}$, 全 氮含量为 $0.11 \%, \mathrm{pH}$ 值约为 8.58 。样方数据(附录: 表 21-24)显示，灌木层总盖度 35\%，高度变化幅度 34-72 cm, 平均高度为 $58 \mathrm{~cm}$, 物种丰富度 3 , 主要 物种为银露梅、蒙古绣线菊、小叶金露梅。草本层 总盖度 $75 \%$, 高度范围0.6-50.2 cm, 平均高度 9.3 $\mathrm{cm}$, 物种丰富度 18 , 主要物种有高山地榆 (Sanguisorba alpina)、小丛红景天(Rhodiola dumulosa)、葛缕子(Carum carvi)、贺兰山毛茛(Ranunculus alaschanicus)、渐尖早熟禾(Poa attenuata)、垂穗披 碱草、阿拉善风毛菊(Saussurea alaschanica)、双花 堇菜(Viola biflora)等。该群落无灌木物种的更新, 苔藓层总盖度为 $0.6 \%$ 。

\section{7 山生柳灌丛(Form. Salix oritrepha)}

土壤为砂壤土, 有机质含量约为 $64.2 \mathrm{~g} \cdot \mathrm{kg}^{-1}$, 全 氮含量为 $0.37 \%, \mathrm{pH}$ 值约为 8.07 。样方数据(附录: 表 25-28)显示，灌木层总盖度 $70 \%$ ，高度变化幅度 20-149 cm, 平均高度为 $81 \mathrm{~cm}$, 物种丰富度 3 , 主要 物种有山生柳 (Salix oritrepha)、鬼箭锦鸡儿 (Caragana jubata)、瘤糖茶蔍子(Ribes himalense var. verruculosum)。草本层总盖度 $30 \%$, 高度范围 0.9-31.4 cm, 平均高度 $7.4 \mathrm{~cm}$, 物种丰富度 17 , 主要 物种有珠芽苶(Polygonum viviparum)、渐尖早熟禾、 小从红景天、祁连薹草(Carex allivenscens)、葛缕子、 阿拉善风毛菊、双花堇菜等。灌木更新层高度范围 3.2-6.1 cm, 平均高度 $4.7 \mathrm{~cm}$, 物种丰富度2, 山生柳 和鬼箭锦鸡儿有更新苗，苔藓层总盖度为 $1.8 \%$ 。

\section{8 鬼箭锦鸡儿灌丛(Form. Caragana jubata)}

土壤为砂粉土, 有机质含量约为 $71.9 \mathrm{~g} \cdot \mathrm{kg}^{-1}$, 全 氮含量为 $0.43 \%, \mathrm{pH}$ 值约为 8.26 。样方数据(附录: 表 29-32)显示, 灌木层总盖度 $65 \%$, 平均高度为 $28 \mathrm{~cm}$, 物种丰富度 1 , 仅有鬼箭锦鸡儿一种灌木。草本层总 盖度 $65 \%$ ，高度范围0.3-12.2 cm, 平均高度 $4.1 \mathrm{~cm}$, 物种丰富度 26 , 主要物种有高山嵩草 (Kobresia pygmaea)、珠芽苶、矮生嵩草(Kobresia humilis)、小 丛红景天、贺兰山延胡索(Corydalis alaschanica)、 直苞风毛菊(Saussurea ortholepis)、垂穗披碱草等。 灌木更新层平均高度 $1.2 \mathrm{~cm}$, 物种丰富度 1 , 鬼箭锦 


\section{鸡儿有更新苗, 无苔蘚层。}

致谢 内蒙古大学苗百龄和董雷博士为野外调查提 供了很多帮助, 旭日博士也为本研究做出了大量的 标本鉴定工作, 在此一并表示感谢!

\section{参考文献}

Hu HF, Wang ZH, Liu GH, Fu BJ (2006). Vegetation carbon storage of major shrublands in China. Journal of Plant Ecology (Chinese Version), 30, 539-544. [胡会峰, 王志 恒, 刘国华, 傅伯杰 (2006). 中国主要灌从植被碳储量. 植物生态学报, 30, 539-544.]

Liang CZ, Zhu ZY, Wang W, Pei H, Zhang T, Wang YL (2004). The diversity and spatial distribution of plant communities in the Helan Mountains. Acta Phytoecologica Sinica, 28, 361-368. [梁存柱, 朱宗元, 王炜, 裴浩, 张 蹈, 王永利 (2004). 贺兰山植物群落类型多样性及其空 间分异. 植物生态学报, 28, 361-368.]

Liu BR (2010). Changes in soil microbial biomass carbon and nitrogen under typical plant communities along an altitudinal gradient in east side of Helan Mountain. Ecology and Environmental Sciences, 19, 883-888. [刘秉儒 (2010). 贺兰山东坡典型植物群落土壤微生物量碳、氮沿海拔梯 度的变化特征. 生态环境学报, 19, 883-888.]

Li ZG, Liang CZ, Wang W, Wang LX, Jia CZ (2012). Plant endemism in the Helanshan Mountains. Journal of Inner Mongolia University (Natural Science Edition), 43, 630-638. [李志刚, 梁存柱, 王炜, 王立新, 贾成朕 (2012). 贺兰山植物区系的特有性. 内蒙古大学学报(自 然科学版), 43, 630-638.]

Zhang WK, Li H, Wang GH (2013). Community characteristics of main vegetation types along two altitudinal transects on mountains of northwestern Beijing, China. Chinese Journal of Plant Ecology, 37, 566-570. [张维康, 李贺, 王国 宏 (2013). 北京西北部山地两个垂直样带内主要植被 类型的群落特征. 植物生态学报, 37, 566-570.]

Zheng JG, Dong DP, Zhao DH, He MZ, Li XR (2008). Relationship between vegetation community characteristics and its environmental factors in the west slope of Helan Mountain. Acta Ecologica Sinica, 28, 4559-4567. [郑敬 刚, 董东平, 赵登海, 何明珠, 李新荣 (2008). 贺兰山 西坡植被群落特征及其与环境因子的关系. 生态学报, 28, 4559-4567.]

Zhu Y, Kang MY, Jiang Y, Liu QR (2008). Altitudinal pattern of species diversity in woody plant communities of Mountain Helan, northwestern China. Journal of Plant Ecology (Chinese Version), 32, 574-581. [ 朱源, 康慕谊, 江源, 刘全儒 (2008). 贺兰山木本植物群落物种多样性的海 拔格局. 植物生态学报, 32, 574-581.]

责任编委: 郭 柯 责任编辑: 李 敏

附录 贺兰山西坡主要山地灌丛群落的基本特征

Supplement Species composition and structure characteristics of the major montane shrub communities in the west slope of Helan Mountains, Nei Mongol, China

http://www.plant-ecology.com/fileup/PDF/cjpe.2018.0111-D1.xls

www.plant-ecology.com 